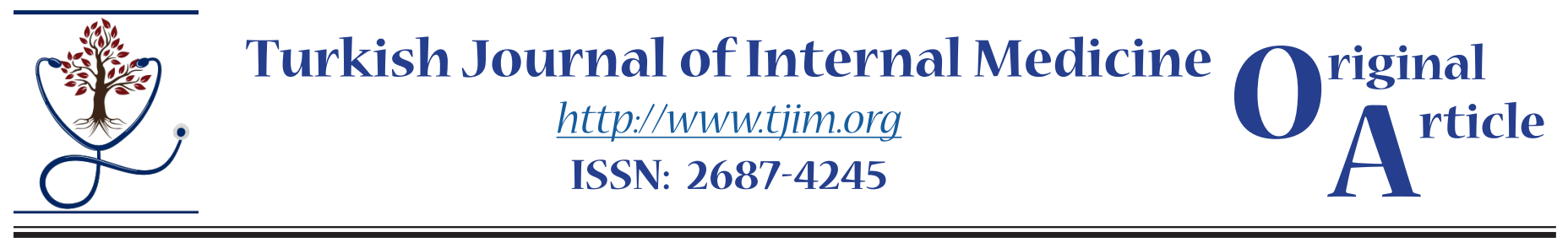

\title{
Effectiveness of Tolvaptan Treatment in Hyponatremic Patients
}

\author{
Emel Isiktas Sayılar, 1 (D) Alparslan Ersoy 2 (D) Yavuz Ayar ${ }^{2,3}$, (D) Mehmet Fethullah Aydin², (D) \\ Mahmut Yavuz 2 (iD) \\ ${ }^{1}$ Division of Nephrology, Department of Internal Medicine, Ufuk University Faculty of Medicine, Ankara, Turkey \\ ${ }^{2}$ Division of Nephrology, Department of Internal Medicine, Bursa Uludag University Faculty of Medicine, Bursa, Turkey \\ ${ }^{3}$ Nephrology Clinic, Bursa City Hospital, Bursa, Turkey
}

\begin{abstract}
Introduction. Non-peptide vasopressin receptor antagonists (vaptans) are effective at increasing sodium in euvolemic and hypervolemic states and appear safe. We aimed to evaluate the efficacy of tolvaptan in euvolemic or hypervolemic hyponatremic patients.

Methods. The study included 9 hyponatremic (serum sodium level $<125 \mathrm{mmol} / \mathrm{L}$ ) patients. Serum potassium levels of all patients were normal and there was no acid-base disturbance. Patients with hypovolemic status and hepatic dysfunction were excluded from the study. Clinical and laboratory data of patients were obtained before and after tolvaptan treatment.

Results. The median age of patients (6 females, 3 males) was 66.63 years (range, 56-82). The mean sodium levels before tolvaptan treatment were $120.5 \mathrm{mEq} / \mathrm{L}$ (SD 2.2, range, 116-124). The mean sodium levels increased significantly to $132.6 \pm 4.0 \mathrm{mEq} / \mathrm{L}$ (range, $125-140$ ) after tolvaptan treatment at $2.7 \pm 1.3$ days (range, 2-6) $(\mathrm{p}<0.001)$. Hyponatremia did not recur after tolvaptan treatment. We did not observe serious adverse event related with tolvaptan treatment.

Conclusion. Hyponatremia was a common problem, and tolvaptan can treat hyponatremia effectively and safely in patients with euvolemic or hypervolemic hyponatremia.
\end{abstract}

Turk J Int Med 2020;2(2): 43-47

DOI: $10.46310 /$ tjim.706226

Keywords: Arginine vasopressin, heart failure, hyponatremia, syndrome of inappropriate antidiuretic hormone secretion, tolvaptan.

\section{Introduction}

Sodium $\left(\mathrm{Na}^{+}\right)$is the major determinant of serum osmolarity and hyponatremia $\left(\mathrm{Na}^{+}<135\right.$ $\mathrm{mEq} / \mathrm{L})$, being the most common electrolyte disorder in hospitalized patients with an incidence of $15-22 \% .^{1}$ Patients with hyponatremia are asymptomatic or have mild symptoms, but in acute severe hyponatremia, serious neurological problems such as seizures, coma and respiratory

Received:March 19,2020; Accepted:April 24,2020; Published Online:April 29,2020 
arrest may develop. ${ }^{2}$ The two most common causes of hypervolemic and euvolemic hyponatremia are heart failure (HF) and syndrome of inappropriate antidiuretic hormone (ADH) secretion (SIADH or Schwartz-Bartter syndrome), respectively. ${ }^{3}$ In patients with $\mathrm{HF}$, the effective circulation volume decreases due to the decrease in cardiac output, while the neurohumoral system, especially AVP and renin angiotensin aldosterone system are active. ${ }^{4}$ Although the effective volume is normal in SIADH, $\mathrm{ADH}$ is released irregularly and uncontrolled or control mechanisms are disrupted due to tumors such as lung cancer, lung diseases, central nervous system diseases and some medications. ${ }^{5}$ Serum $\mathrm{Na}^{+}$concentration is adjusted by arginine vasopressin (AVP, $\mathrm{ADH})$, one of the pituitary hormones, by maintaining a balance between fluid intake and renal fluid excretion. ${ }^{6}$ Under normal conditions, $\mathrm{ADH}$ is released in response to increased plasma osmolarity and decreased intravascular volume or decreased blood pressure. AVP has three different receptors. $\mathrm{V} 1 \mathrm{~A}$ receptor is associated with vasoconstriction and cardiac hypertrophy. V1B receptor is located in anterior pituitary gland, and associated with adrenocorticotropic hormone release. V2 receptor is located in the distal nephron, and increases free water reabsorption and water retention..$^{6,7}$

Conventional approaches in the treatment of euvolemic or hypervolemic hyponatremia are fluid restriction and hypertonic saline infusion with diuretics. However, the effectiveness of fluid restriction is limited and patient compliance is poor. Besides, hypertonic saline infusion can correct sodium levels very quickly or diuretics can cause electrolyte disorders or acute kidney injury. ${ }^{2}$ Vasopressin receptor antagonists bind to the V2 receptor and block the receptor, thereby increasing the concentration of serum $\mathrm{Na}^{+}$and diuresis. Tolvaptan, a vasopressin V2 receptor antagonist, selectively inhibits AVP binding to its receptor in the distal nephron and increases water excretion without disturbing the electrolyte balance. In recent years, tolvaptan has been used successfully in the treatment of hyponatremia in patients with heart failure, cirrhosis or SIADH..$^{8-10}$

This study aimed to investigate the efficacy and safety of tolvaptan therapy on hyponatremia in patients with HF or SIADH.

\section{Methods}

A total of 9 euvolemic or hypervolemic hyponatremic (serum $\mathrm{Na}^{+}$level $<125 \mathrm{mmol} / \mathrm{L}$ ) patients with idiopathic SIADH or HF were included in this study conducted between July 2013 and September 2019. All patients with hypervolemic hyponatremic due to heart failure were initially treated with fluid restriction (1 L/ day) and furosemide infusion and $\mathrm{Na}^{+}$replacement. Patients with heart failure did not have acute myocardial infarction, cardiogenic shock, valve disease or hypotension requiring inotropic support. The diagnosis of SIADH was made with euvolemic hyponatremia, hypoosmolality (serum osmolality $<275 \mathrm{mOsm} / \mathrm{kg}$ ), urine $\mathrm{Na}^{+}$ level above $40 \mathrm{mEq} / \mathrm{L}$ and urine osmolality above $100 \mathrm{mOsm} / \mathrm{kg}$. Kidney, liver, thyroid and adrenal function tests of SIADH patients with euvolemic hyponatremia were within normal ranges, and systolic ejection fractions were measured over $50 \%$ in echocardiographic evaluation. Serum potassium levels of all patients were normal, there was no acid-base disturbance. Patients with hypovolemic status and hepatic dysfunction were excluded from the study.

All patients were started with $15 \mathrm{mg} /$ day tolvaptan treatment (Samsca $15 \mathrm{mg}$ tablet, Abdi Ibrahim Otsuka) with fluid restriction (1 L/day). Diuretic therapy and/or $\mathrm{Na}^{+}$support was not performed simultaneously with tolvaptan. Serum $\mathrm{Na}^{+}$levels were checked 3 times on the first day of tolvaptan therapy and then daily. 24-hour diuresis was monitored and treatment was terminated when serum $\mathrm{Na}^{+}$was $>133 \mathrm{mEq} / \mathrm{L}$. Clinical and laboratory data of patients were obtained before and after treatment.

All statistical analyses were performed using the IBM SPSS Software package of version 23.0 (IBM Corp, Armonk, NY, USA). The data was given as mean \pm standard deviation (SD) or median (min-max). The numerical variables were compared with Wilcoxon signed-rank test within group. Statistical significance was defined by $\mathrm{p}$ $<0.05$. 


\section{Results}

A total of 9 patients (6 females, 3 males) were included. The mean patient age was 66.63 (range, 56 to 82) years Hyponatremia was due to previously diagnosed HF based on clinical and echocardiographic findings in 6 patients, whereas hyponatremia was related to SIADH in 3 patients.

Tolvaptan treatment was associated with significant increase in serum $\mathrm{Na}^{+}$values $(p<0.001)$ and concomitant diuresis amount $(p=0.001)$ (Figure 1) (Friedman's Two-Way Anova by ranks). None of the patients developed an increase in serum $\mathrm{Na}^{+}$concentration over $12 \mathrm{mEq} / \mathrm{L}$ within 48 hours of tolvaptan treatment. Xerostomia and thirst were the only side effects occurred under treatment with no records on other side effects such as confusion, muscle cramps, hypotension, hyperglycemia and liver enzyme elevation. No significant change was noted in serum creatinine levels after tolvaptan treatment $(p=0.522)$ (Wilcoxon test). Dialysis or isolated ultrafiltration was not required in HF patients with low GFR. During the post-discharge 30-day follow up period, $\mathrm{Na}^{+}$levels maintained in the normal range with no need for re-hospitalization due to hyponatremia in any patient.

\section{Discussion}

Hyponatremia is an electrolyte disorders associated with re-hospitalization, prolonged length of hospital stay, increases risk of

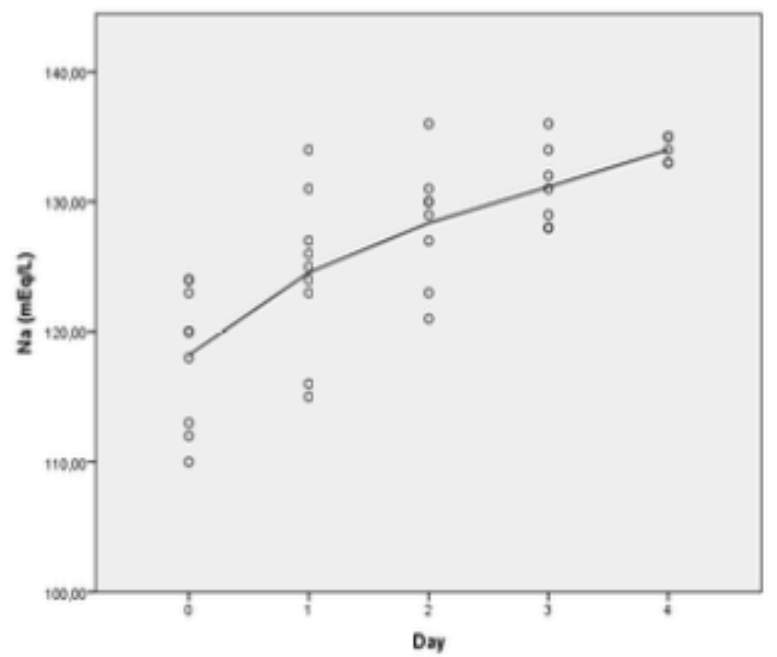

complications and cost increment. The efficacy of tolvaptan treatment in patients with hypervolemic hyponatremia was evaluated for the first time in a study by Gheorghiade et al. in 2003, while later studies and meta-analysis consistently reported the favorable efficacy of tolvaptan in the treatment of hypervolemic or euvolemic hyponatremia. ${ }^{11,12}$ Tolvaptan treatment has been associated with increase in urinary output and serum $\mathrm{Na}^{+}$values along with reduction in hospitalization frequency and complications. ${ }^{13-15}$ Similarly, our findings also revealed significant increase in serum $\mathrm{Na}^{+}$levels and daily diuresis with tolvaptan treatment.

In patients with $\mathrm{HF}$, tolvaptan treatment protects renal functions in most of cases in contrast to diuretic treatment which has adverse effects on renal functions. In two different studies, tolvaptan treatment was reported to be associated with increased diuresis without disturbing renal functions and renal blood flow and without activating sympathetic nervous system and renin angiotensin aldosterone system. ${ }^{9,10}$ Likewise, in the current study, tolvaptan treatment was not associated with renal dysfunction. In another study with 114 decompensated HF patients, authors reported significantly higher 24-hour and 48-hour urinary output and lower risk of poor renal parameters in the conventional plus tolvaptan treatment arm $(n=44)$ as compared with conventional treatment arm $(n=70) .{ }^{16}$ Data from prospective randomized controlled Aquamarine study in 220 acute decompensated $\mathrm{HF}$ patients with GFR of $15-60 \mathrm{~mL} / \mathrm{min}$ revealed superiority

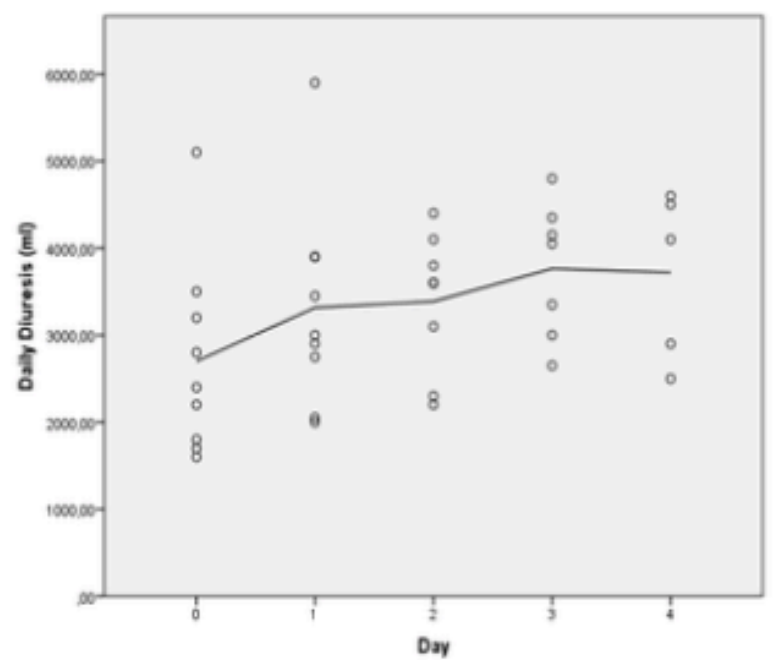

Figure 1. Serum $\mathrm{Na}^{+}$values and urinary output under tolvaptan treatment 
of tolvaptan over furosemide in terms of urinary output, serum $\mathrm{Na}^{+}$concentration and improvement of renal parameters. ${ }^{17}$ In the current study no significant change was noted in renal functions after tolvaptan treatment in patients with low or normal GFR.

DatafromSALT-1 andSALT-2 studiesinpatients with euvolemic or hypervolemic hyponatremia due to inappropriate $\mathrm{ADH}$ syndrome, $\mathrm{HF}$ or cirrhosis, tolvaptan versus placebo was reported to be associated with significantly higher 8-hour and 30-day serum $\mathrm{Na}^{+}$concentrations. ${ }^{18,19}$ Our findings also revealed normal serum $\mathrm{Na}^{+}$levels within 30day post-discharge follow up along with no need for re-hospitalization due to hyponatremia.

Our findings support the past studies indicated xerostomia and thirst as the most common tolvaptan-related side effects, ${ }^{4,15,18,20}$ which were managed via symptomatic approach in our patients.

The major limitations of the current study seem to be the retrospective design, small sample size, lack of control group and a short follow up period.

\section{Conclusions}

In conclusion, while fluid restriction and loop diuretics with hypertonic fluid are treatment options with limited efficacy in euvolemic or hypervolemic hyponatremia, tolvaptan is a safe and effective treatment alternative. Tolvaptan seems to enable shorter length of hospital stay along with reductions in re-hospitalization frequency, dialysis requirement and hyponatremiadependent morbidity and mortality rates. Further large scale studies are necessary to assess the longterm efficacy of tolvaptan on prognosis and renal parameters and to develop the optimal treatment protocol.

\section{Acknowledgement}

None to declare

\section{Conflict of interest}

The authors declared that there are no potential conflicts of interest with respect to the research, authorship, and/or publication of this article. 


\section{References}

1. Verbalis JG. Hyponatremia: endocrinologic causes and consequences of therapy. Trends Endocrinol Metab. 1992 Jan-Feb;3(1):1-7.

2. Park GH, Lee CM, Song JW, Jung MC, Kim JK, Song YR, Kim HJ, Kim SG. Comparison of tolvaptan treatment between patients with the SIADH and congestive heart failure: a single-center experience. Korean J Intern Med. 2018 May;33(3):561-567. doi: 10.3904/kjim.2016.155.

3. Urso C, Brucculeri S, Caimi G. Employment of vasopressin receptor antagonists in management of hyponatraemia and volume overload in some clinical conditions. J Clin Pharm Ther. 2015 Aug;40(4):376-85. doi: $10.1111 /$ jcpt.12279.

4. Lilly LS, Dzau VJ, Williams GH, Rydstedt L, Hollenberg NK. Hyponatremia in congestive heart failure: implications for neurohumoral activation and responses to orthostasis. J Clin Endocrinol Metab. 1984 Nov;59(5):924- 30.

5. Gralla RJ, Ahmad F, Blais JD, Chiodo J 3rd, Zhou W, Glaser LA, Czerwiec FS. Tolvaptan use in cancer patients with hyponatremia due to the syndrome of inappropriate antidiuretic hormone: a posthoc analysis of the SALT-1 and SALT-2 trials. Cancer Med. 2017 Apr;6(4):723-729. doi: $10.1002 /$ cam4.805.

6. Nemerovski C, Hutchinson DJ. Treatment of hypervolemic or euvolemic hyponatremia associated with heart failure, cirrhosis, or the syndrome of inappropriate antidiuretic hormone with tolvaptan: a clinical review. Clin Ther. 2010 Jun;32(6):1015-32. doi: 10.1016/j.clinthera.2010.06.015.

7. Nielsen S, Kwon TH, Christensen BM, Promeneur D, Frøkiaer J, Marples D. Physiology and pathophysiology of renal aquaporins. J Am Soc Nephrol. 1999 Mar;10(3):64763.

8. Schrier RW, Sharma S, Shchekochikhin D. Hyponatraemia: more than just a marker of disease severity? Nat Rev Nephrol. 2013 Jan;9(1):37-50. doi: 10.1038/nrneph.2012.246.

9. Miyazaki T, Fujiki H, Yamamura Y, Nakamura S, Mori T. Tolvaptan, an orally active vasopressin V(2)-receptor antagonist - pharmacology and clinical trials. Cardiovasc Drug Rev. 2007 Spring;25(1):1-13.

10. Costello-Boerrigter LC, Smith WB, Boerrigter G, Ouyang J, Zimmer CA, Orlandi C, Burnett JC Jr. Vasopressin-2receptor antagonism augments water excretion without changes in renal hemodynamics or sodium and potassium excretion in human heart failure. Am J Physiol Renal Physiol. 2006 Feb;290(2):F273-8.

11. Kinugawa K, Sato N, Inomata T. Effects of Tolvaptan on Volume Overload in Patients with Heart Failure. Int Heart J. 2018 Nov 28;59(6):1368-1377. doi: 10.1536/ ihj.18-119.

12. Gheorghiade M, Niazi I, Ouyang J, Czerwiec F, Kambayashi J, Zampino M, Orlandi C; Tolvaptan
Investigators. Vasopressin V2-receptor blockade with tolvaptan in patients with chronic heart failure: results from a double-blind, randomized trial. Circulation. 2003 Jun;107(21):2690-6.

13. Dasta JF, Sundar S, Chase S, Lingohr-Smith M, Lin J. Economicimpact of tolvaptan treatment vs. fluid restriction based on real-world data among hospitalized patients with heart failure and hyponatremia. Hosp Pract (1995). 2018 Oct;46(4):197-202. doi: 10.1080/21548331.2018.1505180.

14. Alskaf E, Tridente A, Al-Mohammad A. Tolvaptan for Heart Failure, Systematic Review and Meta Analysis of Trials. J Cardiovasc Pharmacol. 2016 Sep;68(3):196-203. doi: 10.1097/FJC.0000000000000405.

15. Gheorghiade M, Konstam MA, Burnett JC Jr, Grinfeld L, Maggioni AP, Swedberg K, Udelson JE, Zannad F, Cook T, Ouyang J, Zimmer C, Orlandi C; Efficacy of Vasopressin Antagonism in Heart Failure Outcome Study With Tolvaptan (EVEREST) Investigators. Shortterm clinical effects of tolvaptan, an oral vasopressin antagonist, in patients hospitalized for heart failure: the EVEREST Clinical Status Trials. JAMA. 2007 Mar 28;297(12):1332-43.

16. Matsue Y, Suzuki M, Seya M, Iwatsuka R, Mizukami A, Nagahori W, Ohno M, Matsumura A, Hashimoto Y. Tolvaptan reduces the risk of worsening renal function in patients with acute decompensated heart failure in highrisk population. J Cardiol. 2013 Feb;61(2):169-74. doi: 10.1016/j.jjcc.2012.08.020.

17. Matsue Y, Suzuki M, Nagahori W, Yoshida K, Onishi Y, Satoh Y, Ono Y, Nishioka T, Noda M, Sugi K, Torii S, Tejima T, Sakurada H, Yamaguchi S, Okishige K, Fujii $\mathrm{H}$, Takahashi A. Clinical effectiveness of tolvaptan in patients with acute decompensated heart failure and renal failure: design and rationale of the AQUAMARINE study. Cardiovasc Drugs Ther. 2014 Feb;28(1):73-7. doi: 10.1007/s10557-013-6491-8.

18. Schrier RW, Gross P, Gheorghiade M, Berl T, Verbalis JG, Czerwiec FS, Orlandi C; SALT Investigators. Tolvaptan, a selective oral vasopressin V2-receptor antagonist, for hyponatremia. N Eng1 J Med. 2006 Nov 16;355(20):2099112.

19. Verbalis JG, Adler S, Schrier RW, Berl T, Zhao Q, Czerwiec FS; SALT Investigators. Efficacy and safety of oral tolvaptan therapy in patients with the syndrome of inappropriate antidiuretic hormone secretion. Eur J Endocrinol. 2011 May;164(5):725-32. doi: 10.1530/ EJE10-1078.

20. Gheorghiade M, Gottlieb SS, Udelson JE, Konstam MA, Czerwiec F, Ouyang J, Orlandi C; Tolvaptan Investigators. Vasopressin $\mathrm{v}(2)$ receptor blockade with tolvaptan versus fluid restriction in the treatment of hyponatremia. Am J Cardiol. 2006 Apr 1;97(7):1064-7. 